\title{
The lithium intercalation process in the low-voltage lithium battery anode $\mathrm{Li}_{1+x} \mathrm{~V}_{1-x} \mathrm{O}_{2}$
}

\author{
A. Robert Armstrong ${ }^{1}$, Christopher Lyness ${ }^{1}$, Pooja M. Panchmatia ${ }^{2}$, M. Saiful Islam ${ }^{2 \star}$ \\ and Peter G. Bruce ${ }^{1 \star}$
}

\begin{abstract}
Lithium can be reversibly intercalated into layered $\mathrm{Li}_{1+x} \mathrm{~V}_{1-x} \mathrm{O}_{2}\left(\mathrm{LiCoO}_{2}\right.$ structure) at $\sim 0.1 \mathrm{~V}$, but only if $x>0$. The low voltage combined with a higher density than graphite results in a higher theoretical volumetric energy density; important for future applications in portable electronics and electric vehicles. Here we investigate the crucial question, why Li cannot intercalate into $\mathrm{LiVO}_{2}$ but Li-rich compositions switch on intercalation at an unprecedented low voltage for an oxide? We show that $\mathrm{Li}^{+}$ intercalated into tetrahedral sites are energetically more stable for Li-rich compositions, as they share a face with $\mathrm{Li}^{+}$on the $\mathbf{V}$ site in the transition metal layers. Li incorporation triggers shearing of the oxide layers from cubic to hexagonal packing because the $\mathrm{Li}_{2} \mathrm{VO}_{2}$ structure can accommodate two Li per formula unit in tetrahedral sites without face sharing. Such understanding is important for the future design and optimization of low-voltage intercalation anodes for lithium batteries.
\end{abstract}

$\mathrm{R}$ ecent reports that $\mathrm{Li}$ can be reversibly intercalated into the layered compound $\mathrm{Li}_{1+x} \mathrm{~V}_{1-x} \mathrm{O}_{2}$ (with the $\mathrm{LiCoO}_{2}$ structure) at a potential of $\sim 0.1 \mathrm{~V}$ versus $\mathrm{Li}^{+} / \mathrm{Li}$ represent an important milestone in lithium-ion battery research ${ }^{1-4}$. For almost twenty years graphite has remained the dominant anode in rechargeable lithium-ion batteries; operating by intercalation of Li between the graphene sheets. Efforts to improve on the energy storage of graphite have concentrated on reactions other than intercalation, including silicon and tin anodes that form alloys with $\mathrm{Li}$, conversion/displacement reactions such as $\mathrm{Li}+\mathrm{CoO}$ and extrusion reactions ${ }^{5-26}$. Although work on these alternatives to intercalation has made important progress, and $\mathrm{Sn}-\mathrm{Co}-\mathrm{C}$ alloys are in use, in general, problems of large volume expansion or large voltage hysteresis remain to be solved. As a result, intercalation remains an attractive mechanism for lithium-ion batteries.

Oxide intercalation hosts are attractive because their density is twice that of graphite, leading to double the volumetric energy density, something that is crucial for future applications in electronics and electric vehicles. The lowest voltage oxide intercalation hosts have been the titanates, but their potential is still relatively high at $\sim 1.6 \mathrm{~V}$ versus $\mathrm{Li}^{+} / \mathrm{Li}$, compared with graphite at $\sim 0.1 \mathrm{~V}$, thus halving the overall cell voltage and negating the benefits of using a dense oxide. This is why recent reports that $\mathrm{Li}$ can be intercalated into the layered transition metal oxide $\mathrm{Li}_{1+x} \mathrm{~V}_{1-x} \mathrm{O}_{2}$, at $\sim 0.1 \mathrm{~V}$ and with a theoretical volumetric capacity of $1,360 \mathrm{~mA} \mathrm{~h} \mathrm{~cm}^{-3}$ compared to graphite at $790 \mathrm{~mA} \mathrm{~h} \mathrm{~cm}^{-3}$, are so significant ${ }^{1-4}$. Also, intercalation into an oxide at such a low voltage is unprecedented as usually conversion/displacement reactions dominate in this voltage region ${ }^{20,21}$.

Given the significance of Li intercalation into $\mathrm{Li}_{1+x} \mathrm{~V}_{1-x} \mathrm{O}_{2}$, an important question that arises is why $\mathrm{Li}$ can only be intercalated into lithium-rich $\mathrm{Li}_{1+x} \mathrm{~V}_{1-x} \mathrm{O}_{2}$, that is for $x>0$ (refs 1,2). Here we investigate the intercalation process for $\mathrm{Li}_{1+x} \mathrm{~V}_{1-x} \mathrm{O}_{2}$ and in particular the key role of non-stoichiometry in switching on intercalation, using a combination of powder X-ray and neutron diffraction along with advanced computational methods.

\section{Initial characterization}

$\mathrm{Li}_{1+x} \mathrm{~V}_{1-x} \mathrm{O}_{2}$ was prepared by solid state reaction as described in the Methods section. Powder X-ray diffraction patterns for $x=0$, 0.03 and 0.07 are shown in Fig. 1a. All peaks may be indexed on the basis of the $\alpha-\mathrm{NaFeO}_{2}\left(\mathrm{LiCoO}_{2}\right)$ crystal structure, space group $R \overline{3} m$. The materials are highly crystalline, exhibiting sharp diffraction peaks $\left(\mathrm{FWHM}=0.11^{\circ}\right.$ in $2 \theta$ for the $(104)$ reflection of $x=0.07$ ). These results are consistent with the particle sizes observed by electron microscopy, Fig. 1b, which are typically $100-200 \mathrm{~nm}$ and with Brunauer-Emmett-Teller (BET) surface areas of $1-5 \mathrm{~m}^{2} \mathrm{~g}^{-1}$. Compositions were confirmed by structure refinement, inductively coupled plasma (ICP) and vanadium oxidation state analysis, as discussed later.

\section{Structures of the as-prepared materials}

To understand the intercalation process, and in particular why extra $\mathrm{Li}$ in the structure is necessary to facilitate intercalation, it is first necessary to establish the structures of the as-prepared materials. Rietveld refinement, employing combined X-ray and neutron diffraction data, because $\mathrm{Li}$ is insensitive to $\mathrm{X}$-rays and $\mathrm{V}$ is insensitive to neutrons, was carried out on $\mathrm{LiVO}_{2}$ and $\mathrm{Li}_{1.07} \mathrm{~V}_{0.93} \mathrm{O}_{2}$, based on a structural model derived from $\mathrm{LiCoO}_{2}\left(\alpha-\mathrm{NaFeO}_{2}\right)$ in which Co was replaced by $\mathrm{V}$. The only positional parameter not constrained by symmetry is the $z$ coordinate of $\mathrm{O}$; this was allowed to vary freely. In view of the insensitivity of $\mathrm{V}$ to neutrons the temperature factor for the transition metal site was fixed in the course of the refinements; those of all other sites were varied independently. The cation distribution was investigated by refining $\mathrm{Li}$ and $\mathrm{V}$ on the transition metal, $3 \mathrm{a}$, and alkali metal, $3 \mathrm{~b}$, sites of the $R \overline{3} \mathrm{~m}$ space group. In the case of the stoichiometric material, no occupancy of $\mathrm{V}$ on the alkali metal sites was observed; therefore, in the final refinements only $\mathrm{Li}$ was located on the alkali metal sites. The occupancy of the transition metal sites was 0.99/0.01(1) V/Li. The final refined composition was $\mathrm{LiVO}_{2}$ within one standard deviation. For $\mathrm{Li}_{1.07} \mathrm{~V}_{0.93} \mathrm{O}_{2}$, again no occupancy of the alkali metal sites by $\mathrm{V}$ was detected, only $\mathrm{Li}$. The $\mathrm{Li}$ and $\mathrm{V}$ 

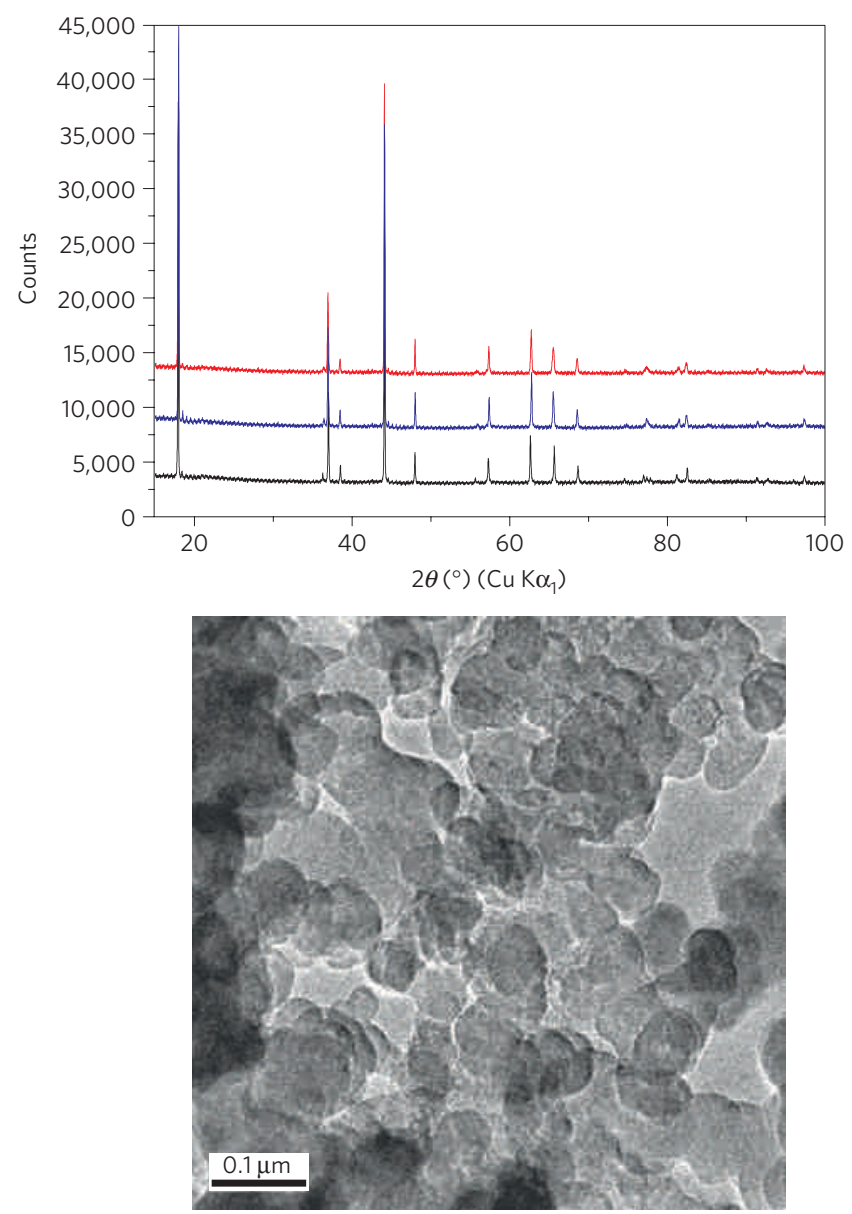

Figure 1 | Structural characterization of as-prepared $\mathrm{Li}_{1+x} \mathbf{V}_{1-x} \mathrm{O}_{2}$. a, Powder $X$-ray diffraction patterns of as-prepared $\mathrm{Li}_{1+x} \mathrm{~V}_{1-x} \mathrm{O}_{2}$. Black, red and blue lines correspond to $x=0, x=0.03$ and $x=0.07$ respectively. b, Transmission electron micrograph for as-prepared $\mathrm{Li}_{1.07} \mathrm{~V}_{0.93} \mathrm{O}_{2}$.

occupancy on the transition metal sites were varied independently, giving values of 0.92(1) and 0.08(1) and a composition $\mathrm{Li}_{1.08} \mathrm{~V}_{0.92} \mathrm{O}_{2}$. The final parameters are presented in Supplementary Table S1 along with the corresponding R-factors, which indicate excellent fits. The fitted profiles are available as Supplementary Fig. S1. Chemical analysis was carried out by ICP, following the procedure described in the Methods section. Compositions of $\mathrm{Li}_{1.01} \mathrm{~V}_{0.99} \mathrm{O}_{2}$ and $\mathrm{Li}_{1.07} \mathrm{~V}_{0.93} \mathrm{O}_{2}, \pm 0.02$ were obtained. Oxidation state analysis by redox titration, also described in the Methods section, gave values of +3.03 and $+3.16 \pm 0.05$ respectively. The compositions derived from the ICP and oxidation state analyses are, within errors, in accord with those derived from the refined data, Supplementary Table S1.

\section{The intercalation process}

Considering first stoichiometric $\mathrm{LiVO}_{2}$, the load curve, Fig. 2, exhibits a short plateau at $0.8 \mathrm{~V}$ corresponding to the potential of electrolyte reduction observed previously for graphite and other low voltage anodes ${ }^{27-29}$. The low voltage plateau is very short $\left(\sim 40 \mathrm{~mA} \mathrm{~h}^{-1}\right)$, occurs at $0 \mathrm{~V}$; there is no corresponding plateau on charge and no cycling. No change in the X-ray or neutron diffraction patterns was observed up to the end of discharge, consistent with the absence of intercalation into the stoichiometric material. There was no evidence of reduced vanadium phases, such as $\mathrm{V}$ or $\mathrm{VO}$, or of $\mathrm{Li}_{2} \mathrm{O}$ that might have indicated a conversion reaction. This was also the case for the non-stoichiometric material, confirming the absence of conversion/displacement reactions.

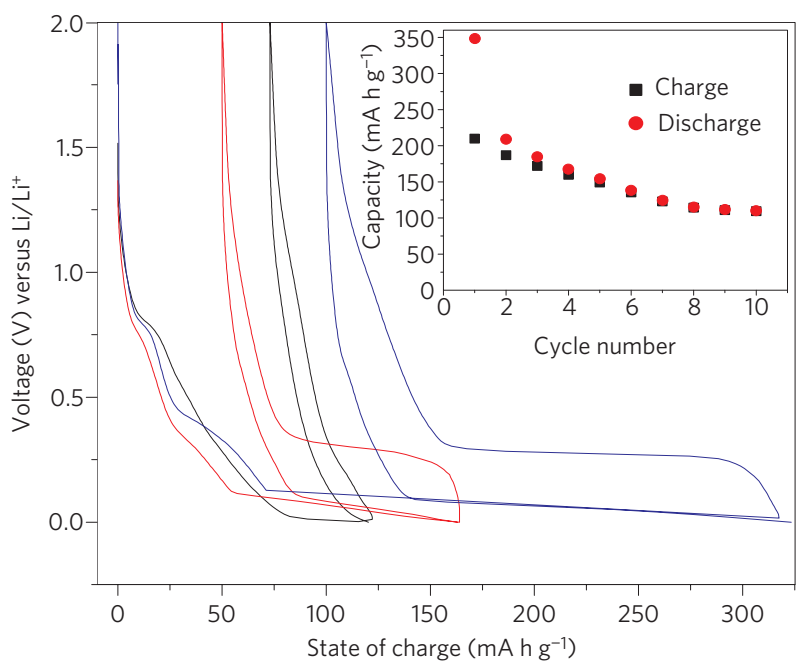

Figure 2 | Variation of potential (versus $\mathrm{Li}^{+}[1 \mathrm{M}] / \mathrm{Li}$ ) with state of charge for $\mathrm{Li}_{1+x} \mathbf{V}_{1-x} \mathbf{O}_{2}$. Rate $10 \mathrm{~mA} \mathrm{~g}^{-1}$; black, red and blue lines correspond to $x=0, x=0.03$ and $x=0.07$ respectively. Inset shows variation of capacity with cycle number for $x=0.07$.

Turning to $\mathrm{Li}_{1.07} \mathrm{~V}_{0.93} \mathrm{O}_{2}$, it also exhibits a short plateau at $0.8 \mathrm{~V}$, Fig. 2. However, in contrast to $\mathrm{LiVO}_{2}$, the low voltage plateau is extensive, commences at $\sim 0.1 \mathrm{~V}$ with a slight downward slope, possesses a corresponding plateau on charge (lithium extraction) and the material can be cycled (inset Fig. 2). The observed fading of capacity on cycling may be due to the volume change ( $25 \%)$ and to the two-phase nature of the intercalation reaction; the combination of which leads to strain at the interface between the two phases. However, the composite electrode structure (for example distribution of conducting matrix) may also play a role. Better capacity retention has been reported ${ }^{30}$. The extent of the low voltage plateau increases markedly with increasing lithium content up to $x=0.07$, more lithium-rich compositions do not exhibit higher discharge capacities. The load curves are similar to previous reports ${ }^{1-4}$.

Powder neutron diffraction patterns collected at various points along the charge/discharge curve for $x=0.07$ are shown in Fig. 3. Commencing with discharge, the powder neutron diffraction pattern after the passage of $25 \mathrm{mAh} \mathrm{g}^{-1}$, that is just after the $0.8 \mathrm{~V}$ plateau, is identical to that of the as-prepared material, in accord with the $0.8 \mathrm{~V}$ process being associated with reduction of the electrolyte, as described above. The sloping region of the load curve from 35 to $70 \mathrm{~mA} \mathrm{~h} \mathrm{~g}^{-1}$ has been attributed previously to further solid electrolyte interphase (SEI) layer formation/electrolyte reduction on the surfaces of the composite electrode materials ${ }^{1,2}$. This may be so to some extent, but neutron diffraction data collected at the end of the sloping region, Fig. 3, show evidence of a new phase, co-existing with the as-prepared phase, and with a similar structure, but with the extra $\mathrm{Li}$ in tetrahedral sites in the Li layers. Such intercalation into the tetrahedral sites in the ccp structure is predicted by the modelling studies discussed later. Further detailed studies are required to fully explore and hence understand the process taking place in these early stages of the load curve, whereas the focus of the present paper is the low voltage plateau.

The diffraction data at $160 \mathrm{~mA} \mathrm{~h} \mathrm{~g}^{-1}$ and at the end of discharge both exhibit the presence of two phases, with the proportions of these phases varying as expected for a two-phase intercalation reaction. One phase possesses the structure of the as-prepared material and the diffraction data for the other corresponds to $\mathrm{Li}_{2} \mathrm{VO}_{2}$. This second phase is isostructural with previously reported materials, including $\mathrm{Li}_{2} \mathrm{NiO}_{2}, \mathrm{Li}_{2} \mathrm{MnO}_{2}$ and $\mathrm{Li}_{2} \mathrm{Mn}_{0.5} \mathrm{Ni}_{0.5} \mathrm{O}_{2}$, which 


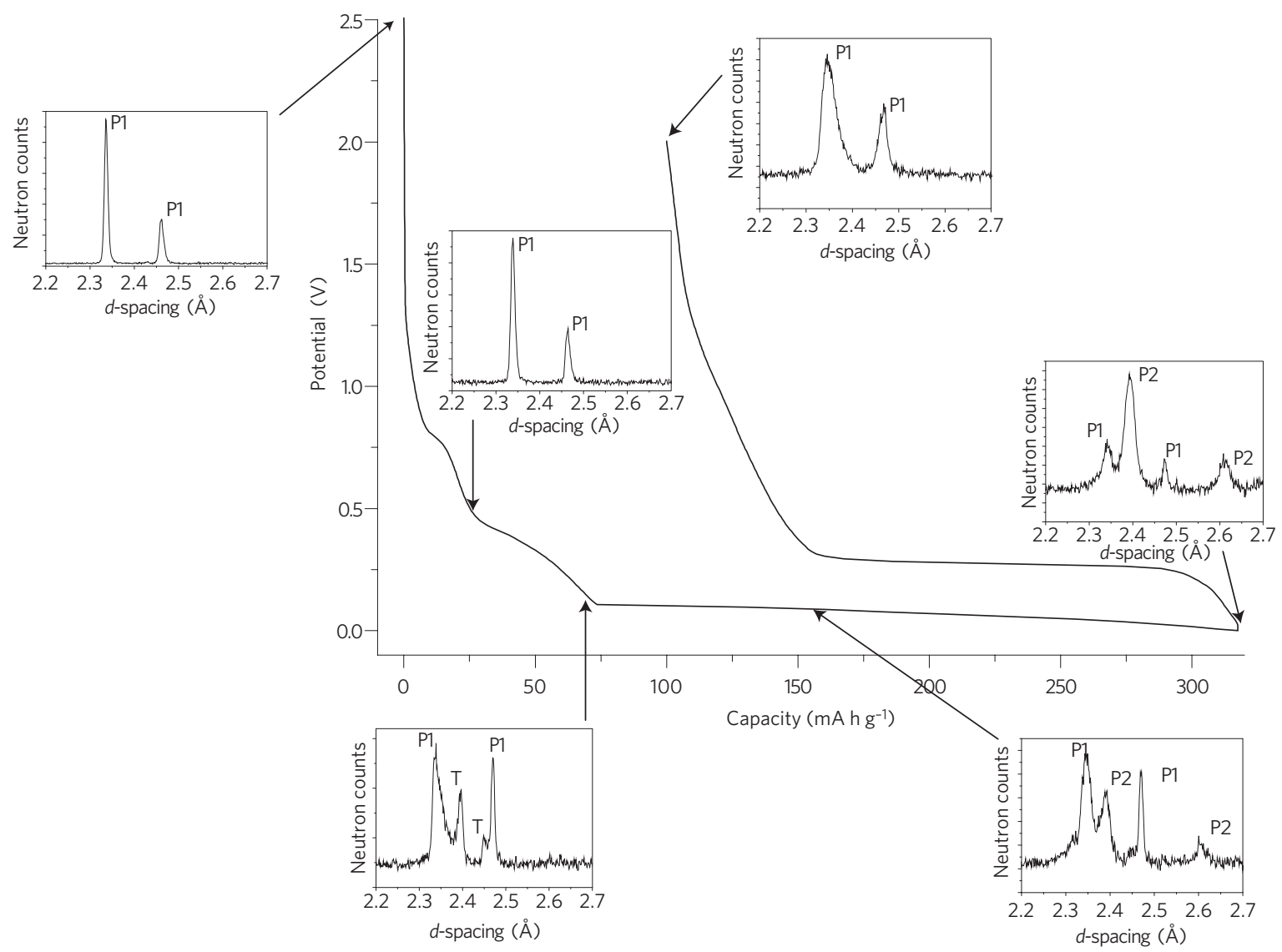

Figure 3 | Expanded regions of the powder neutron diffraction patterns collected at various states of charge for $\mathrm{Li}_{1.07} \mathrm{~V}_{0.93} \mathrm{O}_{2}$. $\mathrm{P} 1$ and $\mathrm{P} 2$ are prominent peaks of the host structure and $\mathrm{Li}_{2} \mathrm{VO}_{2}$ respectively whilst $\mathrm{T}$ represents an intermediate phase containing tetrahedral lithium ions. The asymmetry of the peak at $2.4 \AA$ in the charged material may be due to a small amount of residual $\mathrm{Li}_{2} \mathrm{VO}_{2}$ phase. Note that neutron counts are in arbitrary units.

are also derived by intercalation into the corresponding layered $\mathrm{LiMO}_{2}$ phases but with the crucial difference that the voltage is $>1 \mathrm{~V}$ in these cases ${ }^{31-35}$. Note that even at the end of discharge, $0 \mathrm{~V}$ cut-off, two phases remain, as shown in Fig. 3.

Two phase refinements were carried out using combined powder $\mathrm{X}$-ray and neutron diffraction data collected on the $x=0.07$ material at $160 \mathrm{mAhg}^{-1}$ and full discharge. The fitted profiles are available as supplementary data, Supplementary Fig. S2, and demonstrate that the fit is good. Crystallographic parameters for the new, $\mathrm{Li}_{2} \mathrm{VO}_{2}$, phase are presented in Supplementary Table S2. The structure of $\mathrm{Li}_{2} \mathrm{VO}_{2}$ is composed of hexagonal close packed oxide ions with vanadium ions occupying alternate sheets of octahedral sites between the oxide ion layers and lithium ions occupying all of the tetrahedral sites in the intervening layers, Fig. 4. On charging the cell to $2 \mathrm{~V}$, the $\mathrm{Li}_{2} \mathrm{VO}_{2}$ phase converts back to the original structure. High-resolution transmission electron microscopy data collected on samples discharged to $160 \mathrm{~mA} \mathrm{~h}^{-1}$, Supplementary Fig S3, are consistent with the presence of two phases in the material. Overall the combined X-ray and neutron refinements confirm that $\mathrm{Li}$ intercalation occurs via a 2-phase mechanism between $\mathrm{LiVO}_{2}$ and $\mathrm{Li}_{2} \mathrm{VO}_{2}$ (refs 1,2).

On the basis of the ratios of the two phases extracted from fitting the powder diffraction data at $160 \mathrm{~mA} \mathrm{~h} \mathrm{~g}^{-1}$ and at the end of discharge, the amount of lithium intercalated as the discharge proceeds along the plateau has been calculated. The analysis indicates that the amount of intercalated lithium corresponds to charges of 65 and $166 \mathrm{mAh}^{-1}$ respectively, compared with the actual charges passed along the plateau of 90 and $240 \mathrm{~mA} \mathrm{~h} \mathrm{~g}^{-1}$. Clearly, the charge passed on progressing along the discharge plateau exceeds the amount of lithium inserted into the structure,

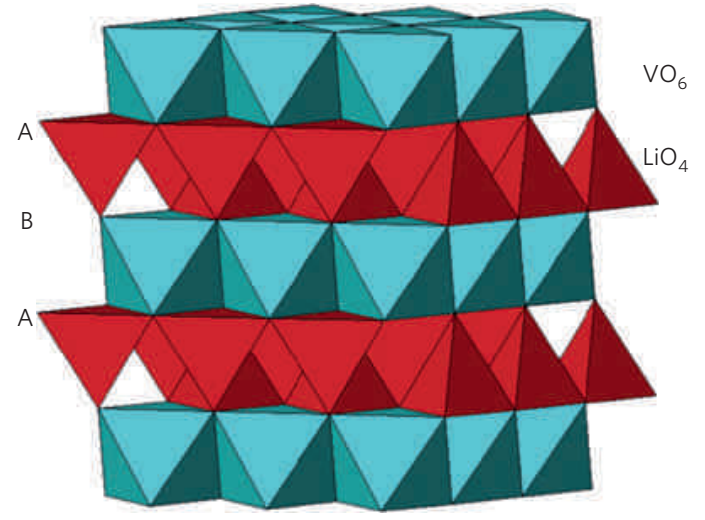

Figure 4 | Schematic representation of the structure of $\mathrm{Li}_{2} \mathbf{V O}_{2} \cdot \mathrm{LiO}_{4}$ tetrahedra (red), $\mathrm{VO}_{6}$ octahedra (blue).

and this discrepancy increases with increasing depth of discharge, the difference being $25 \mathrm{~mA} \mathrm{~h} \mathrm{~g}^{-1}$ and $74 \mathrm{~mA} \mathrm{~h} \mathrm{~g}^{-1}$ respectively.

A reduction process in addition to Li intercalation is taking place along the plateau. This may involve more SEI layer formation or the formation of soluble products from electrolyte reduction. The difference between the lengths of the charge and discharge plateaux for the $x=0.07$ composition is similar to the discrepancy between the lithium content and charge passed along the first discharge plateau. This is consistent with the excess capacity on the first discharge plateau being associated with an irreversible process, such that the magnitude of the subsequent charging plateau is less than discharge. It is noteworthy that the efficiency on subsequent cycles is 


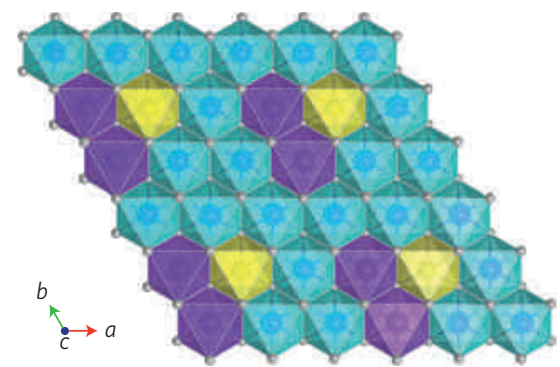

c

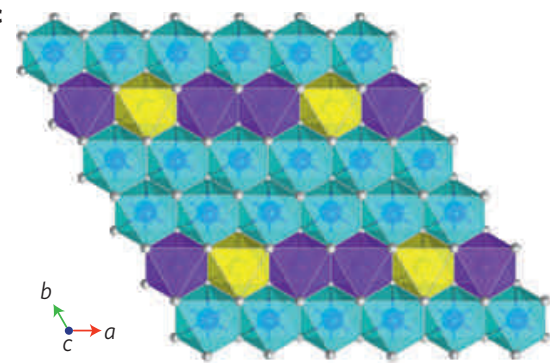

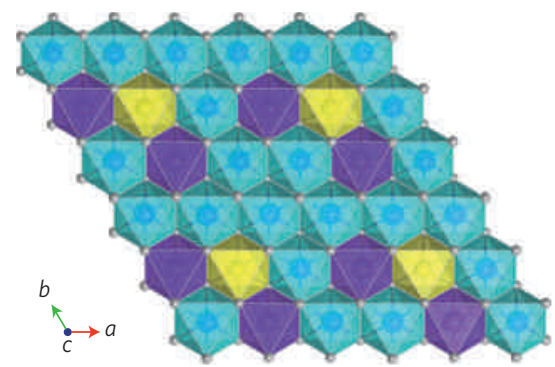

d

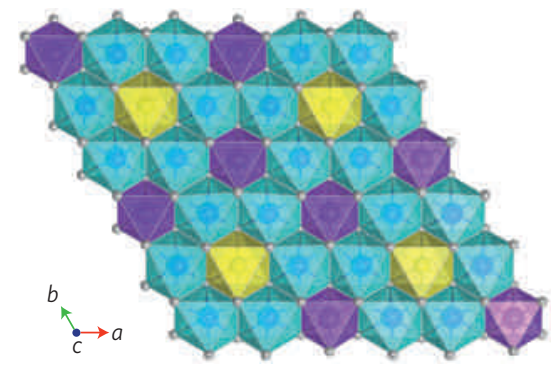

Figure $\mathbf{5}$ | Configurations of $2 \mathrm{~V}_{\mathrm{V}}^{4+}$ and $\mathrm{Li}_{\mathrm{v}}^{+}$in the vanadium layer of $\mathrm{Li}_{1.07} \mathrm{~V}_{0.93} \mathrm{O}_{2}$. Configurations $\mathbf{a}-\mathbf{c}$ are trimer clusters of nearest-neighbour ions, and configuration d shows isolated species (yellow: $\mathrm{Li}_{V}^{+} ;$blue: $\mathrm{V}_{V}^{3+} ;$ purple: $\mathrm{V}_{V}^{4+}$ ).

much closer to $100 \%$, further indicating that the irreversible process occurs mainly on the first discharge. The incomplete conversion of ccp to hcp on the first discharge may be due to polarization; the greater the polarization the earlier the low voltage cut-off will be reached. We have observed small variations in the polarization between cells, with conversions of up to $70 \%$. Detailed work on optimizing the composite electrode structure should help to maximize the conversion. In the case of $x=0.03$ material, the discharge plateau is shorter than that for $x=0.07$ and the difference between the charge and discharge plateaux is correspondingly less.

\section{The role of non-stoichiometry}

Why is it that $\mathrm{Li}$ cannot intercalate into stoichiometric $\mathrm{LiVO}_{2}$, yet a relatively small amount of excess lithium can switch on a large capacity to intercalate lithium at low voltages? Given the low rate used in Fig. 2, it is unlikely to be the result of differences in transport properties between the stoichiometric and lithium-rich compositions, that is to differences in ionic or electronic transport. This view is supported by galvanostatic intermittent titration technique (GITT) pseudo-equilibrium measurements, which show the same behaviour as in Fig. 2. The 2-phase intercalation process involves shearing of the close packed oxide ion layers from cubic to hexagonal stacking. The structure of stoichiometric $\mathrm{LiVO}_{2}$ shows no evidence of $\mathrm{V}$ in the Li layers (site exchange), so the inability to intercalate $\mathrm{Li}$ into stoichiometric $\mathrm{LiVO}_{2}$ is not due to $\mathrm{V}$ pinning the alkali metal layers together and inhibiting shearing.

To investigate the difference between stoichiometric and nonstoichiometric materials further, atomistic modelling methods were employed, being well-established tools in the study of defect structures in complex oxides ${ }^{36-38}$. First, the crystal structures of $\mathrm{LiVO}_{2}, \mathrm{Li}_{1.07} \mathrm{~V}_{0.93} \mathrm{O}_{2}$ and $\mathrm{Li}_{2} \mathrm{VO}_{2}$ were reproduced and exhibit good agreement with the experimental structures (see Supplementary Table S3). Simulations of intrinsic defects in stoichiometric $\mathrm{LiVO}_{2}$ find an unfavourable formation energy of more than $3 \mathrm{eV}$ for $\mathrm{Li} / \mathrm{V}$ site exchange (comprised of isolated $\mathrm{Li}^{+}$on the $\mathrm{V}$ sites, $\mathrm{Li}_{\mathrm{V}}^{+}$, and isolated $\mathrm{V}^{3+}$ on the $\mathrm{Li}^{+}$sites, $\mathrm{V}_{\mathrm{Li}}^{3+}$ ); this is clearly in accord with the above observation from Rietveld refinement that there is no $\mathrm{V}$ in the $\mathrm{Li}$ layers.

Formation of the solid solution $\mathrm{Li}_{1+x} \mathrm{~V}_{1-x} \mathrm{O}_{2}$ involves the mechanism $3 \mathrm{~V}_{\mathrm{V}}^{3+}+\mathrm{Li}^{+}=2 \mathrm{~V}_{\mathrm{V}}^{4+}+\mathrm{Li}_{\mathrm{V}}^{+}$, that is substitution of $\mathrm{V}^{3+}$ by $\mathrm{Li}^{+}$on the octahedral $\mathrm{V}$ site and charge compensation by oxidation of two other $\mathrm{V}^{3+}$ to $\mathrm{V}^{4+}$. Effective charges are expected to favour the two $\mathrm{V}^{4+}$ occupying the nearest neighbour (nn) sites that each share an edge with the $\mathrm{Li}_{\mathrm{V}}^{+}$site. Modelling studies have investigated the energetics of several configurations of the $2 \mathrm{~V}_{\mathrm{V}}^{4+}$ and $\mathrm{Li}_{\mathrm{V}}^{+}$in the $\mathrm{V}$ layer of $\mathrm{Li}_{1.07} \mathrm{~V}_{0.93} \mathrm{O}_{2}$ (shown in Fig. 5); the energies listed in Supplementary Table $\mathrm{S} 4$ confirm the stability of the $\left(2 \mathrm{~V}_{\mathrm{V}}^{4+} / \mathrm{Li}_{\mathrm{V}}^{+}\right)$trimer cluster compared with isolated defects. Although the small energy differences do not allow us to distinguish between the three trimer configurations, Fig. $5 \mathrm{a}-\mathrm{c}$ (the energy differences are small compared with $\mathrm{kT}$ at the temperature of synthesis, $850^{\circ} \mathrm{C}$ ), the results clearly indicate a non-random distribution of $\mathrm{V}_{\mathrm{V}}^{4+}$ and $\mathrm{Li}_{\mathrm{V}}^{+}$in the vanadium layers.

There is scope for the trimer clusters to coalesce into larger clusters. Each $\mathrm{Li}_{\mathrm{V}}^{+}$site is surrounded by six edge sharing $\mathrm{V}$ sites. We therefore explored how the $\mathrm{V}^{4+}$ could be distributed around the $\mathrm{Li}_{\mathrm{V}}^{+}$to form larger clusters, which included a dodecamer (or 'flower-like') arrangement in which all six of the edge sharing sites surrounding $\mathrm{Li}_{\mathrm{V}}^{+}$are $\mathrm{V}^{4+}$. However, the most stable configurations (shown in Supplementary Figs S4 and S5) are still less favourable than the trimer clusters by more than $350 \mathrm{meV}$. In general, the calculations on the $\mathrm{Li}_{1.07} \mathrm{~V}_{0.93} \mathrm{O}_{2}$ composition indicate that the $\left(2 \mathrm{~V}_{\mathrm{V}}^{4+} / \mathrm{Li}_{\mathrm{V}}^{+}\right)$trimer is the most favourable arrangement compared to larger, more complex, clusters.

Turning to the intercalation of $\mathrm{Li}$ into $\mathrm{LiVO}_{2}$ and $\mathrm{Li}_{1.07} \mathrm{~V}_{0.93} \mathrm{O}_{2}$, $\mathrm{Li}^{+}$must first be inserted into a tetrahedral site, as all the octahedral sites are already occupied. In the case of $\mathrm{LiVO}_{2}$ the most favourable empty tetrahedral site is located in the alkali metal layers, and shares one face with a $\mathrm{V}^{3+}$ ion in an octahedral site in the transition metal layers, Fig. 6a. In contrast, in $\mathrm{Li}_{1+x} \mathrm{~V}_{1-x} \mathrm{O}_{2}$ the intercalated $\mathrm{Li}^{+}$can occupy a tetrahedral site in the alkali metal layer that shares a face with the $\mathrm{Li}^{+}$in the $\mathrm{Li}_{\mathrm{V}}^{+}$site, Fig. $6 \mathrm{~b}$. Atomistic modelling calculations have probed the energies for lithium ion occupancy at these two sites (Table 1); note that the lowest energy trimer structure was used for the calculations on $\mathrm{Li}_{1.07} \mathrm{~V}_{0.93} \mathrm{O}_{2}$. The relative energies clearly indicate that the intercalated $\mathrm{Li}^{+}$at the site sharing a face with $\mathrm{Li}_{\mathrm{V}}^{+}$in $\mathrm{Li}_{1.07} \mathrm{~V}_{0.93} \mathrm{O}_{2}$ is about $620 \mathrm{meV}$ lower in energy than for $\mathrm{Li}^{+}$ in $\mathrm{LiVO}_{2}$, rendering the intercalation of $\mathrm{Li}$ into the lithium-rich $\mathrm{Li}_{1.07} \mathrm{~V}_{0.93} \mathrm{O}_{2}$ much more favourable.

Previous density functional theory (DFT) studies $^{39-44}$ on a variety of oxide electrode materials have shown that such methods 


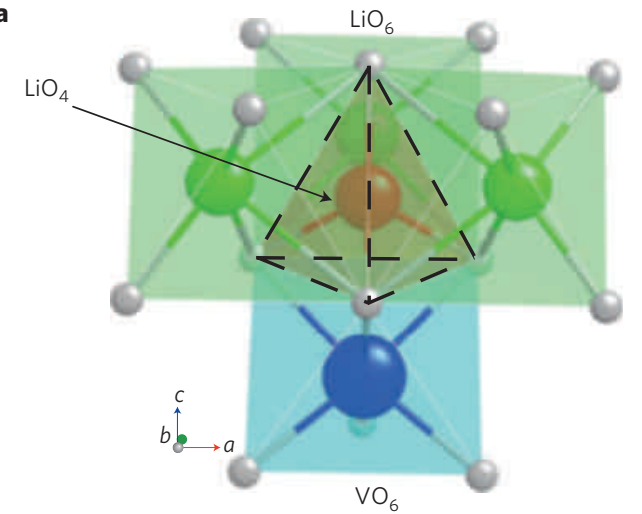

b

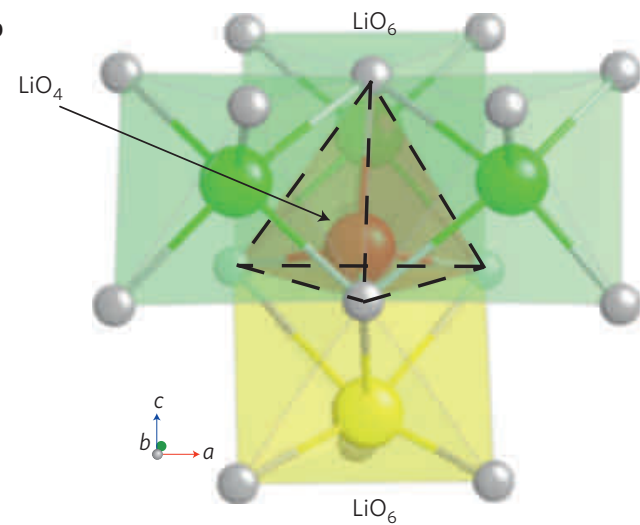

Figure 6 | Calculated local structures around an inserted $\mathrm{Li}+$ ion in $\mathrm{LiVO}_{2}$ and $\mathrm{Li}_{1.07} \mathrm{~V}_{0.93} \mathrm{O}_{2}$. Dotted lines highlight its local coordination: $\mathbf{a}, \mathrm{Li}^{+}$at a tetrahedral site in an alkali metal layer of the $\mathrm{LiVO}_{2}$ structure and sharing a face with a $\mathrm{V}$ ion in an octahedral site in the layer below (the other three faces of the tetrahedron are shared with $\mathrm{Li}$ in octahedral sites in the alkali metal layers); $\mathbf{b}, \mathrm{Li}^{+}$at a tetrahedral site in an alkali metal layer of the $\mathrm{Li}_{1.07} \mathrm{~V}_{0.93} \mathrm{O}_{2}$ structure and sharing a face with a $\mathrm{Li}$ ion in an octahedral site in the layer below (the other three faces of the tetrahedron are shared with $\mathrm{Li}$ in octahedral sites in the alkali metal layers). The inserted $\mathrm{Li}^{+}$in $\mathrm{Li}_{1.07} \mathrm{~V}_{0.93} \mathrm{O}_{2}$ is displaced by $\sim 0.3 \AA$ from the centre of the tetrahedron towards the shared face with $\mathrm{Li}_{V}^{+}$. The adjacent $\mathrm{Li}_{V}^{+}$ion is also displaced away by $\sim 0.6 \AA$ from the inserted lithium leading to a distorted coordination environment.

are well suited to probing lithium insertion properties and to predicting precise trends in cell voltages. Here we derived cell voltages for lithium intercalation into the stoichiometric $\mathrm{LiVO}_{2}$ and the Li-rich $\mathrm{Li}_{1+x} \mathrm{~V}_{1-x} \mathrm{O}_{2}$ systems using the total energies from a series of structural optimizations. Table 1 indicates a negative cell voltage of $-2.98 \mathrm{~V}$ for $\mathrm{Li}_{1+y} \mathrm{VO}_{2}$, confirming that the intercalation of lithium into the stoichiometric oxide is unfavourable; lithium plating would occur, at $0 \mathrm{~V}$, before the voltage for intercalation was reached. This result is consistent with the above experimental data, which show no evidence of intercalation into stoichiometric $\mathrm{LiVO}_{2}$, and with previous reports ${ }^{1,2}$. In contrast, for Li intercalation into $\mathrm{Li}_{1.07} \mathrm{~V}_{0.93} \mathrm{O}_{2}$ a cell voltage of $+0.58 \mathrm{~V}$ is derived, indicating intercalation into this phase is possible. This is consistent with the neutron diffraction data, discussed above, where evidence for $\mathrm{Li}$ intercalation into the tetrahedral sites in the ccp structure was observed; although the calculated voltage is somewhat greater than the average for the sloping region of the discharge curve.

The simulations also produce valuable local structural information, which can be difficult to extract from diffraction experiments alone. Figure 6 indicates that the inserted $\mathrm{Li}^{+}$in $\mathrm{Li}_{1.07} \mathrm{~V}_{0.93} \mathrm{O}_{2}$ is displaced slightly from the centre of the tetrahedron towards the
Table 1 | Calculated energies for intercalated $\mathrm{Li}^{+}$and cell voltages for stoichiometric and Li-rich structures.

Energies of intercalated $\mathrm{Li}^{+}$at sites shown in Fig. 6.

\begin{tabular}{|c|c|c|c|}
\hline Compound & Insertion site & $\mathrm{E}\left(\mathrm{Li}^{+}\right)(\mathrm{meV})$ & $\Delta \mathrm{E}^{\star}(\mathrm{meV})$ \\
\hline $\mathrm{VO}_{2}$ & $\mathrm{~V}_{\mathrm{V}}^{3+}$ & -3552 & +618 \\
\hline Li-rich $\mathrm{Li}_{1.07} \mathrm{~V}_{0.93} \mathrm{O}_{2}$ & $\mathrm{Li}^{+}$adjacent to $\mathrm{Li}_{V}^{+}$ & -4170 & 0 \\
\hline
\end{tabular}

Average cell voltages

Composition/range Cell voltage (V)

Stoichiometric $\mathrm{Li}_{1+y} \mathrm{VO}_{2}(0.0<y<0.07)-2.98$

Li-rich $\mathrm{Li}_{1.07+y} \mathrm{~V}_{0.93} \mathrm{O}_{2}(0.0<y<0.07) \quad+0.58$

Li-rich $\mathrm{Li}_{1.07+y} \mathrm{~V}_{0.93} \mathrm{O}_{2}(0.0<y<0.93) \quad+0.23$

*Energy difference between these sites with reference to the most stable site.

shared face with $\mathrm{Li}_{\mathrm{V}}^{+}$, leading to three $\mathrm{Li}^{+}-\mathrm{O}$ distances of $1.8 \AA$ and one of $2.1 \AA$. Owing to $\mathrm{Li}^{+}-\mathrm{Li}^{+}$repulsions the adjacent $\mathrm{Li}_{\mathrm{V}}^{+}$ion is also displaced away from the inserted lithium, leading to a separation of $2.1 \AA$ between the two lithium ions. Interestingly, the $\mathrm{Li}_{\mathrm{V}}^{+}$ion now sits in a distorted coordination environment of three short $\mathrm{Li}_{\mathrm{V}}^{+}-\mathrm{O}$ and three long $\mathrm{Li}_{\mathrm{V}}^{+}-\mathrm{O}$ distances of about $1.91 \AA$ and $2.45 \AA$ respectively (compared to the initial octahedral coordination of $6 \times 1.99 \AA$ ). Li insertion has also perturbed the local anion sublattice with lengthening of several O-O distances from $2.93 \AA$ to more than $3.0 \AA$. The inserted lithium therefore causes large distortions to the local structure of $\mathrm{Li}_{1.07} \mathrm{~V}_{0.93} \mathrm{O}_{2}$, which could be viewed as precursors to the shearing of oxide layers for cubic to hexagonal packing.

Although the tetrahedral site in the Li layer of $\mathrm{Li}_{1.07} \mathrm{~V}_{0.93} \mathrm{O}_{2}$ is more stable than in $\mathrm{LiVO}_{2}$ it does share all four faces with $\mathrm{Li}^{+}$ions in octahedral sites ( 3 in the alkali metal layers and the $\mathrm{V}$ site substituted by $\mathrm{Li}, \mathrm{Li}_{\mathrm{V}}^{+}$). The resultant $\mathrm{Li}^{+}-\mathrm{Li}^{+}$repulsions trigger the shearing of the close packed oxide ion layers from $\mathrm{ABC}$ to the $\mathrm{AB}$ stacking of the hexagonal close packed $\mathrm{Li}_{2} \mathrm{VO}_{2}$ structure. $\mathrm{AB}$ stacking can accommodate all of the original Li plus one extra Li per formula unit in the tetrahedral sites of the alkali metal layers (there are twice the number of tetrahedral sites to octahedral sites per alkali metal layer), Fig. 4. The tetrahedral sites share faces with empty tetrahedral sites in the transition metal layers and empty octahedral sites in the alkali metal layers, that is there is no face sharing of occupied sites, leading to a stable structure. By this mechanism it is possible to understand why a small degree of vanadium substitution by lithium can trigger a marked capacity to insert lithium via a 2-phase mechanism.

DFT studies have been extended to calculate the voltage expected for the 2-phase reaction, and give a value of $+0.23 \mathrm{~V}$, Table 1, in good accord with the low voltage plateau commencing at $\sim 0.1 \mathrm{~V}$. As with previous DFT studies ${ }^{39-41}$, there are small quantitative differences with experimental values, which have been attributed largely to the overestimation of the calculated binding energy for lithium metal. In any case, our calculated trend in cell voltages as a function of structure and stoichiometry confirms the important role that the lithium-rich composition plays in initiating lithium intercalation, and accords well with the electrochemical measurements.

It is interesting to consider the implications of the present work for other layered $\mathrm{LiMO}_{2}$ compounds. The results presented here indicate that the presence of $\mathrm{Li}$ on the transition metal sites should favour Li intercalation and transformation of ccp to hcp in layered compounds. It is noteworthy that compounds such as $\mathrm{Li}\left(\mathrm{Li}_{0.02} \mathrm{Mn}_{0.46} \mathrm{Ni}_{0.46} \mathrm{Ti}_{0.05}\right) \mathrm{O}_{2}$, with $\mathrm{Li}$ on the transition metal sites, can readily intercalate $\mathrm{Li}$ with a marked capacity associated with the ccp to hcp transformation ${ }^{34,35}$. In contrast, $\mathrm{Li}$ cannot be 
intercalated into $\mathrm{LiCoO}_{2}$. However, further work is required to corroborate this trend.

In conclusion, the process of lithium intercalation into $\mathrm{Li}_{1+x} \mathrm{~V}_{1-x} \mathrm{O}_{2}$ has been investigated by a combination of computational methods along with powder X-ray and neutron diffraction, focussing in particular on the role that excess lithium plays on switching on intercalation. Whereas $\mathrm{Li}$ cannot be intercalated into stoichiometric $\mathrm{LiVO}_{2}$, substituting as little as $3 \%$ of the $\mathrm{V}$ on the transition metal sites by $\mathrm{Li}$ is sufficient to promote a 2-phase intercalation process between cubic close packed $\mathrm{LiVO}_{2}$ and hexagonal close packed $\mathrm{Li}_{2} \mathrm{VO}_{2}$ at potentials of $\sim 0.1 \mathrm{~V}$. The process may be reversed on charging (Li extraction). The results show that the inability to intercalate into stoichiometric $\mathrm{LiVO}_{2}$ is not due to the presence of site-exchange disorder involving $\mathrm{V}$ ions in the alkali metal layers pinning them together, as might have been thought. Instead, we show that substitution of $\mathrm{Li}$ for $\mathrm{V}$ on the octahedral transition metal sites renders tetrahedral sites in the alkali metal layers energetically accessible by Li, which in turn triggers the shearing of the cubic close-packed oxide ion layers to hexagonal close packing such that two Li per formula unit can be accommodated without face sharing.

Given the importance that $\mathrm{Li}$ intercalation into $\mathrm{Li}_{1+x} \mathrm{~V}_{1-x} \mathrm{O}_{2}$ at $\sim 0.1 \mathrm{~V}$ has for lithium battery anodes, and that this occurs only for the Li-rich compositions, the results presented in this paper provide a framework not only for understanding the intercalation process but also for the future design and optimization of low voltage intercalation oxides as anodes for rechargeable lithium batteries.

\section{Methods}

$\mathrm{Li}_{1+x} \mathrm{~V}_{1-x} \mathrm{O}_{2}$ was synthesized from lithium carbonate and vanadium oxide using a solid state method. Appropriate ratios of dried $\mathrm{V}_{2} \mathrm{O}_{3}$ (Aldrich, 99\%) and $\mathrm{Li}_{2} \mathrm{CO}_{3}$ (Aldrich, $99+\%$ ) powders were mixed together, placed in a gas-tight container and subsequently ball-milled for $60 \mathrm{~min}$ (SPEX Centri-Prep 8,000 M mixer/mill). The mixture was then placed in an alumina crucible, covered with a lid and heated at $800^{\circ} \mathrm{C}$ for $10 \mathrm{~h}$ under flowing argon. The compound was allowed to cool to room temperature, then heated to $850^{\circ} \mathrm{C}$ for $12 \mathrm{~h}$ under a flowing gas mixture of $95 \%$ argon $/ 5 \%$ hydrogen to complete the reaction and obtain a single phase product.

Chemical analysis was carried out by ICP using a Perkin-Elmer Optima 7300DV ICP-OES. The samples of lithium vanadium oxide were carefully weighed out, dissolved in hot aqua regia and then diluted before analysis for Li and V. ICP analysis was carried out by an external company (Butterworths Ltd.). Vanadium oxidation state analysis was performed by double titration following the method described in ref. 45. After dissolution in $\mathrm{H}_{2} \mathrm{SO}_{4}$, the $\mathrm{V}^{3+}$ and $\mathrm{V}^{4+}$ content in the sample was determined by titration (V1) with aqueous $\mathrm{KMnO}_{4}(0.01 \mathrm{M})$. An aqueous solution of $\mathrm{FeSO}_{4}\left(\mathrm{NH}_{4}\right)_{2} \mathrm{SO}_{4} \cdot 6 \mathrm{H}_{2} \mathrm{O}$ was then added to reduce all the $\mathrm{V}^{5+}$ to $\mathrm{V}^{4+}$. The solution was cooled in an ice bath and an excess of $\left(\mathrm{NH}_{4}\right)_{2} \mathrm{~S}_{2} \mathrm{O}_{8}$ was added to oxidize $\mathrm{Fe}^{2+}$ to $\mathrm{Fe}^{3+}$. Finally, $\mathrm{V}^{4+}$ was titrated (V2) with $\mathrm{KMnO}_{4}(0.01 \mathrm{M})$ to measure the total vanadium content of the sample. The average oxidation state of vanadium was given by $5-(\mathrm{V} 1) /(\mathrm{V} 2)$. Errors, based on the above volumetric analysis are estimated to be $\pm 5 \%$.

Composite electrodes were fabricated using the active material, super $\mathrm{S}$ carbon and Kynar Flex 2801 (a co-polymer based on PVDF) binder in a mass ratio of 75:18:7. Electrochemical cells consisting of a $\mathrm{Li}_{1+x} \mathrm{~V}_{1-x} \mathrm{O}_{2}$ composite electrode, a lithium metal counter electrode and the electrolyte, a 1 molar solution of $\mathrm{LiPF}_{6}$ in ethylene carbonate-dimethyl carbonate 1:1 ((v/v) (Merck)), were constructed and handled in an Ar-filled MBraun glovebox. Electrochemical measurements were conducted using a Biologic Macpile II multichannel instrument. Samples for neutron diffraction were prepared electrochemically. After cycling, cells were transferred to an argon-filled glove box before opening and active material removed. The electrodes were then rinsed with a small amount of dry solvent to remove residual electrolyte. They were left under dynamic vacuum overnight to ensure all solvent had evaporated. The samples were then transferred to $2 \mathrm{~mm}$ quartz capillaries.

BET surface areas were determined using a Hiden IGA porosimeter. Powder $\mathrm{X}$-ray diffraction patterns were obtained on pristine material using a Stoe STADI/P diffractometer employing $\mathrm{Cu} \mathrm{K} \alpha_{1}$ radiation operating in transmission mode. Data from cycled materials were obtained on a similar diffractometer with the samples sealed in capillaries. Time-of-flight powder neutron diffraction data were collected on the POLARIS high-intensity, medium resolution instrument at ISIS, Rutherford Appleton Laboratory (UK). The structures were refined by the Rietveld method using TOPAS Academic ${ }^{46}$. TEM studies were carried out using a JEOL JEM-2011 with an accelerating voltage of $200 \mathrm{keV}$. TEM images were recorded by a Gatan CCD camera in a digital format.
The two principal computational methods employed were atomistic defect modelling and DFT, which have been applied successfully to other complex oxides $^{36-44}$. Atomistic defect simulations were performed using the GULP code ${ }^{47}$ based on effective interatomic potentials (Supplementary Table S5), and the shell model to describe electronic polarizability. An important feature is the modelling of lattice relaxation around the point defect, treated by the Mott-Littleton approach ${ }^{38}$. Solid state DFT calculations were performed using the VASP (ref. 48) code, within which the core electrons were represented by ultra-soft pseudopotentials ${ }^{49}$, and the Perdew-Wang (PW91) density functional ${ }^{50}$ was used for exchange-correlation. Introduction of Coulombic on-site correlations through GGA $+U$ is now a well-established approach for transition metal compounds, for which we have used $U$ values of $4 \mathrm{eV}$ and $6.75 \mathrm{eV}$ for $\mathrm{V}$ (III) and $\mathrm{V}$ (II) phases respectively. We note that previous first-principles calculations find strong $\mathrm{V}(3 \mathrm{~d})-\mathrm{O}(2 \mathrm{p})$ mixing in $\mathrm{Li}_{1.1} \mathrm{~V}_{0.9} \mathrm{O}_{2}$ (ref. 51) Integration over the Brillouin zone was carried out with $4 \times 4 \times 4$ Monkhorst-Pack grids for geometry optimization calculations on $2 \times 2 \times 1$ supercells of $\mathrm{LiVO}_{2}, \mathrm{Li}_{1.07} \mathrm{~V}_{0.93} \mathrm{O}_{2}$ and $\mathrm{Li}_{2} \mathrm{VO}_{2}$. A large cut-off energy of $600 \mathrm{eV}$ was used to ensure effective convergence. The initial unit cells for the geometry optimizations were taken from our experimental structural data (Supplementary Tables S1 and S2).

Received 6 July 2010; accepted 18 January 2011; published online 13 February 2011

\section{References}

1. Choi, N. S., Kim, J. S., Yin, R. Z. \& Kim, S. S. Electrochemical properties of lithium vanadium oxide as an anode material for lithium-ion battery. Mater. Chem. Phys. 116, 603-606 (2009).

2. Song, J. H. et al. Electrochemical characteristics of lithium vanadate, $\mathrm{Li}_{1+x} \mathrm{VO}_{2}$, new anode materials for lithium ion batteries. J. Power Sources 195, 6157-6161 (2010).

3. Kim, S-S., Kim, J., Koike, M. \& Kobayashi, N. 14th International Meeting on Lithium Batteries, Tianjin, China, Abstr. \#20 (2008).

4. Kim, S-S., Nitta, Y., Nedoseykina, T. I. \& Lee, J-C. US Patent Application US 2006/0088766 (2006).

5. Armand, M. \& Tarascon, J-M. Building better batteries. Nature 451, 652-657 (2008).

6. Nazri, G-A. \& Pistoia, G. (eds) Lithium Batteries Science and Technology (Kluwer Academic/Plenum, 2004).

7. Arico, A. S., Bruce, P. G., Scrosati, B., Tarascon, J. M. \& Van Schalkwijk, W. Nanostructured materials for advanced energy conversion and storage devices. Nature Mater. 4, 366-377 (2005).

8. Bruce, P. G., Scrosati, B. \& Tarascon, J. M. Nanomaterials for rechargeable lithium batteries. Angew. Chem. Int. Ed. 47, 2930-2946 (2008).

9. Huggins, R. A. in Handbook of Battery Materials (ed. Besenhard, J. O.) (Wiley-VCH, 1999) Part III, Chapter 4.

10. Winter, M. \& Besenhard, J. O. Electrochemical lithiation of tin and tin-based intermetallic and composites. Electrochim. Acta 45, 31-50 (1999).

11. Mao, O. \& Dahn, J. R. Mechanically alloyed $\mathrm{Sn}-\mathrm{Fe}(-\mathrm{C})$ powders as anode materials for $\mathrm{Li}$ ion batteries. III. $\mathrm{Sn}_{2} \mathrm{Fe}: \mathrm{SnFe}_{3} \mathrm{C}$ active/inactive composites. J. Electrochem. Soc. 146, 423-427 (1999).

12. Beaulieu, L. Y. \& Dahn, J. R. The reaction of lithium with Sn-Mn-C intermetallics prepared by mechanical alloying. J. Electrochem. Soc. 147, 3237-3241 (2000).

13. Magasinski, A. et al. High-performance lithium-ion anodes using a hierarchical bottom-up approach. Nature Mater. 9, 353-358 (2010).

14. Amadei, I., Panero, S., Scrosati, B., Cocco, G. \& Schiffini, L. The $\mathrm{Ni}_{3} \mathrm{Sn}_{4}$ intermetallic as a novel electrode in lithium cells. J. Power Sources 143, 227-230 (2005)

15. Graetz, J., Ahn, C. C., Yazami, R. \& Fuetz, B. Highly reversible lithium storage in nanostructured silicon. Electrochem. Solid-State Lett. 6, A194-A197 (2003).

16. Yang, J. et al. Si/C composites for high capacity lithium storage materials. Electrochem. Solid-State Lett. 6, A154-A156 (2003).

17. Chan, C. K. et al. High-performance lithium battery anodes using silicon nanowires. Nature Nanotech. 3, 31-35 (2008).

18. Kepler, K. D., Vaughey, J. T. \& Thackeray, M. M. $\mathrm{Li}_{x} \mathrm{Cu}_{6} \mathrm{Sn}_{5}(0<x<13)$ : An intermetallic insertion electrode for rechargeable lithium batteries. Electrochem. Solid-State Lett. 2, 307-309 (1999).

19. Fransson, L. M. L. et al. Phase transitions in lithiated $\mathrm{Cu}_{2} \mathrm{Sb}$ anodes for lithium batteries: An in situ X-ray diffraction study. Electrochem. Commun. 3, 317-323 (2001)

20. Poizot, P., Laruelle, S., Grugeon, S., Dupont, L. \& Tarascon, J-M. Nano-sized transition metal oxides as negative electrode material for lithium-ion batteries. Nature 407, 496-499 (2000).

21. Leroux, F., Coward, G. R., Power, W. P. \& Nazar, L. F. Understanding the nature of low-potential Li uptake into high volumetric capacity molybedenum oxides. Electrochem. Solid-State Lett. 1, 255-258 (1998).

22. Taberna, P. L., Mitra, S., Poizot, P., Simon, P. \& Tarascon, J. M. High rate capabilities $\mathrm{Fe}_{3} \mathrm{O}_{4}$-based $\mathrm{Cu}$ nano-architectured electrodes for lithium-ion battery applications. Nature Mater. 7, 567-573 (2006). 
23. Pereira, N., Dupont, L., Tarascon, J. M, Klein, L. C. \& Amatucci, G. G. Electrochemistry of $\mathrm{Cu}_{3} \mathrm{~N}$ with lithium - A complex system with parallel processes. J. Electrochem. Soc. 150, A1273-A1280 (2003).

24. Li, H., Ritcher, G. \& Maier, J. Reversible formation and decomposition of LiF clusters using transition metal fluorides as precursors and their application in rechargeable Li batteries. Adv. Mater. 15, 736-739 (2003).

25. Badway, F., Cosandey, F., Pereira, N. \& Amatucci, G. G. Carbon metal fluoride nanocomposites: High capacity reversible metal fluoride conversion materials as rechargeable positive electrodes for Li batteries. J. Electrochem. Soc. 150, A1318-A1327 (2003).

26. Pralong, V., Souza, D. C. S., Leung, K. T. \& Nazar, L. Reversible lithium uptake by $\mathrm{CoP}_{3}$ at low potential: Role of the anion. Electrochem. Commun. 4, 516-520 (2002).

27. Peled, E. The electrochemical-behaviour of alkali and alkaline-earth metals in non-aqueous battery systems - the solid electrolyte interphase model. J. Electrochem. Soc. 126, 2047-2051 (1979).

28. Fong, R., von Sacken, U. \& Dahn, J. R. Studies of lithium intercalation into carbons using nonaqueous electrochemical-cells. J. Electrochem. Soc. 137, 2009-2013 (1990).

29. Besenhard, J. O., Winter, M., Yang, J. \& Biberacher, W. Filming mechanism of lithium-carbon anodes in organic and inorganic electrolytes. J. Power Sources 54, 228-231 (1995).

30. Park, S-Y., Choi, N-S., Yew, K-H., Lee, D-K. \& Kim, S-S. US Patent Application US 2009/0068566 (2009).

31. David, W. I. F., Goodenough, J. B., Thackeray, M. M. \& Thomas, M. G. S. R. The crystal-structure of $\mathrm{Li}_{2} \mathrm{MnO}_{2}$. Rev. Chim. Miner. 20, 636-642 (1983).

32. Dahn, J. R., Von Sacken, U. \& Michal, C. A. Structure and electrochemistry of $\mathrm{Li}_{1+/-\gamma} \mathrm{NiO}_{2}$ and a new $\mathrm{Li}_{2} \mathrm{NiO}_{2}$ phase with the $\mathrm{Ni}(\mathrm{OH})_{2}$ structure. Solid State Ion. 44, 87-97 (1990).

33. Davidson, I., Greedan, J. E., Von Sacken, U., Michal, C. A. \& Dahn, J. R. Structure of $1 \mathrm{~T}-\mathrm{Li}_{2} \mathrm{NiO}_{2}$ from powder neutron-diffraction. Solid State Ion. 46, 243-247 (1991).

34. Johnson, C. S. et al. The role of $\mathrm{Li}_{2} \mathrm{MO}_{2}$ structures $(\mathrm{M}=$ metal ion $)$ in the electrochemistry of $(x) \mathrm{LiMn}_{0.5} \mathrm{Ni}_{0.5} \mathrm{O}_{2} \cdot(1-x) \mathrm{Li}_{2} \mathrm{TiO}_{3}$ electrodes for lithium-ion batteries. Electrochem. Commun. 4, 492-498 (2002).

35. Johnson, C. S. et al. Structural characterization of layered $\mathrm{Li}_{x} \mathrm{Ni}_{0.5} \mathrm{Mn}_{0.5} \mathrm{O}_{2}$ $(0<x \leq 2)$ oxide electrodes for Li batteries. Chem. Mater. 15, 2313-2322 (2003).

36. Islam, M. S., Driscoll, D. J., Fisher, C. A. J. \& Slater, P. R. Atomic-scale investigation of defects, dopants and lithium transport in the $\mathrm{LiFePO}_{4}$ olivine-type battery material. Chem. Mater 17, 5085-5092 (2005).

37. Kendrick, E., Kendrick, J., Knight, K. S., Islam, M. S. \& Slater, P. R. Cooperative mechanisms of fast-ion conduction in gallium-based oxides with tetrahedral moieties. Nature Mater. 6, 871-874 (2007).

38. Catlow, C. R. A. (ed.) Computer Modelling in Inorganic Crystallography (Academic, 1997)

39. Zhou, F., Cococcioni, M., Marianetti, C. A., Morgan, D. \& Ceder, G. First principles prediction of redox potentials in transition-metal compounds with LDA + U. Phys. Rev. B 70, 235121 (2004).
40. Kang, K. S., Meng, Y. S., Breger, J., Grey, C. P. \& Ceder, G. Electrodes with high power and high capacity for rechargeable lithium batteries. Science 311, 977-980 (2006).

41. Arrouvel, C., Parker, S. C. \& Islam, M. S. Lithium insertion and transport in the $\mathrm{TiO}_{2}-\mathrm{B}$ anode material: A computational study. Chem. Mater. 21, 4778-4783 (2009).

42. Braithwaite, J. S., Catlow, C. R. A., Gale, J. D., Harding, J. H. \& Ngoepe, P. E. Calculated cell discharge curve for lithium batteries with a $\mathrm{V}_{2} \mathrm{O}_{5}$ cathode. J. Mater. Chem. 10, 239-240 (2000).

43. Scanlon, D. O., Walsh, A., Morgan, B. J. \& Watson, G. W. An ab initio study of reduction of $\mathrm{V}_{2} \mathrm{O}_{5}$ through the formation of oxygen vacancies and $\mathrm{Li}$ intercalation. J. Phys. Chem. C 112, 9903-9911 (2008).

44. Meng, Y. S. \& Arroyo-de Dompablo, M. E. First principles computational materials design for energy storage materials in lithium ion batteries. Energy Environ. Sci. 2, 589-609 (2009).

45. Hodnett, B.K., Permanne, $\mathrm{Ph}$. \& Delmon, B. Influence of $\mathrm{p} / \mathrm{v}$ ratio on the phase composition and catalytic activity of vanadium phosphate based catalysts. Appl. Catalys. 6, 231-244 (1983).

46. Coelho, A. A. Whole-profile structure solution from powder diffraction data using simulated annealing. J. Appl. Crystallogr. 33, 899-908 (2000).

47. Gale, J. D. \& Rohl, A. L. The general utility lattice program. Mol. Simul. 29, 291-341 (2003).

48. Kresse, G. \& Furthmüller, J. Efficient iterative schemes for ab initio total-energy calculations using a plane-wave basis set. Phys. Rev. B 54, 11169 (1996).

49. Vanderbilt, D. Soft self-consistent pseudopotentials in a generalized eigenvalue formalism. Phys. Rev. B 41, 7892-7895 (1990).

50. Burke, K., Perdew, J. P. \& Wang, Y. in Electronic Density Functional Theory: Recent Progress and New Directions (eds Dobson, J. F. \& Vignale, G.) (Plenum, 1998).

51. Yin, R. Z., Kim, Y. S., Choi, W. U., Kim, S. S. \& Kim, H. J. Structural analysis and first-principles calculation of lithium vanadium oxide for advanced $\mathrm{Li}$-ion batteries. Adv. Quantum Chem. 54, 23-33 (2008).

\section{Acknowledgements}

P.G.B. and M.S.I. are indebted to the European Union and EPSRC for financial support. The computations were run on the HECToR facilities via the Materials Chemistry Consortium.

\section{Author contributions}

A.R.A. and C.L. carried out the experimental work and data analysis, P.M.P. the modelling, M.S.I. and P.G.B. conceived and directed the project.

\section{Additional information}

The authors declare no competing financial interests. Supplementary information accompanies this paper on www.nature.com/naturematerials. Reprints and permissions information is available online at http://npg.nature.com/reprintsandpermissions. Correspondence and requests for materials should be addressed to M.S.I or P.G.B. 